\title{
Physics Language Anxiety among Students in Introductory Physics Course
}

\author{
Rex Taibu ${ }^{1^{*}}$, Franca Ferrari-Bridgers ${ }^{1}$ \\ ${ }^{1}$ Queensborough Community College of The City University of New York, USA
}

Received 24 March 2019 • Revised 23 August 2019 • Accepted 28 August 2019

\begin{abstract}
In this research an instrument was developed to measure students' anxiety about the jargon of physics. Levels of anxiety were then compared with student content performance and general classroom anxiety. Anxiety levels were also compared based on students' language of origin (native vs. nonnative English speaking students). Statistical analyses indicated that the created instrument was reliable and that a larger percentage of students admitted that the vocabulary of physics creates anxiety in their physics learning and that fear of communication apprehension was prevalent than fear of peer evaluation. There was a negative but small correlation between anxiety about physics vocabulary and student course performance. The correlation between anxiety about physics vocabulary and general classroom anxiety was moderate. There was no significant difference in levels of anxiety between native and nonnative Englishspeaking students. A comparison between results of this research and previous studies (theories) sheds more light into the implications for conducting studies relating to academic anxiety.
\end{abstract}

Keywords: introductory physics, scientific language, vocabulary anxiety

\section{INTRODUCTION}

Students learn new terminology in an introductory physics course which helps them to better understand the physics concepts. While physics terminology is chosen to improve communication in the subject, sometimes it can hinder the learning process.

Related difficulties in learning physics concepts arise due to the use of ambiguous terms such as "weight" (Taibu, Schuster, \& Rudge, 2017; Taibu, 2015) as well as conflict between every day and scientific language (Williams, 1999). Consequently, students usually find it hard to understand science concepts and to participate in classroom discussions. Thus the vocabulary of physics has the potential to create anxiety among introductory level physics students since most of these students are taking physics for the first time.

A closer look into how students feel about how science is communicated may shed more light into factors impeding the acquisition of physics concepts. Further, knowing the level and scope of students' anxiety about the vocabulary of physics may potentially provide a platform to resolve/minimize the issues. A closely related research area has been that of "language anxiety" that students experience when learning a new language such as anxiety about learning English (Cebreros, 2003), or anxiety about leaning French (Gardner, 1985) or Spanish (Horwitz, Horwitz, \& Cope, 1986). Horwitz, Horwitz, and Cope (1986) defined Foreign Language Anxiety (FLA) as "a distinct complex of self-perceptions, beliefs, feelings, and behaviors related to classroom language learning arising from the uniqueness of the (foreign) language learning process." (p. 128). Horwitz et al. (1986) asserts that FLA comprises three components: communication apprehension, fear of negative evaluation, and test anxiety. A closer look at "FLA" studies seems to indicate that scientific language may be regarded as "foreign language" because it is new to students (Rosenthal, 1996) and there is a need to inquire more about the level and scope of anxiety that students may have about physics language. Thus, the aim of this exploratory research was to create an instrument (i) to measure anxiety about physics vocabulary, (ii) to explore students' anxiety levels with regards to how physics is

(C) 2020 by the authors; licensee Modestum Ltd., UK. This article is an open access article distributed under the terms and conditions of the Creative Commons Attribution License (http://creativecommons.org/licenses/by/4.0/). $\square$ Rtaibu@qcc.cuny.edu (*Correspondence) $\square$ Fferrari@qcc.cuny.edu 


\section{Contribution of this paper to the literature}

- This research developed a Physics Vocabulary Classroom Anxiety Scale (PVCAS) for measuring students' anxiety about the jargon of physics and adds new insights into literature on conceptual and terminological issues in science education.

- The PVCAS might help education researchers to gauge the level and scope of anxiety that students have about the vocabulary of physics, and consequently plan ways to minimize the fear.

- Several controversies exit in the literature regarding the relationship between academic anxiety and other variables. The current research adds more insight into the latter controversy and specifically provides suggestions on how to interpret academic anxiety studies.

communicated, and (iii) to inquire if there are any relationships between students' vocabulary anxiety and other variables such as their content understanding and general classroom anxiety.

\section{LITERATURE REVIEW}

Anxiety is described as the subjective feeling of tension, apprehension, nervousness, and worry, or a feeling of one's own weakness and inability to deal with real or imaginary extortions (Spielberger, 1983; Wolman, 1973). Usually anxiety is classified into two types: trait anxiety and state anxiety, where trait anxiety refers to the general anxiety that an individual may have while state anxiety refers to anxiety that an individual may have in specific situations such as test taking or during mathematics learning (Phillips, 1992). Trait anxiety is related to a natural tendency of a person to be anxious; a more stable character to be anxious. On the other hand, state anxiety relates to uneasiness that is experienced at a particular moment in times as a reaction to specific situation (Ellis, 2008; Horikawa, \& Yagi, 2012; Horwitz, Horwitz, \& Cope, 1986; Randler, 2009; Spielberger, 1996).

Regardless of the kind of anxiety, previous research has acknowledged that students are anxious about various academic issues. Several issues may create anxiety or worry among students such that several researchers have delved into exploring students' anxiety levels with a hope to provide a solution to such anxiety. Anxiety related research has taken various forms including the study of science anxiety (Mallow, 1978), math anxiety (Suinn, \& Edwards, 1982), writing anxiety (Yaman, 2010), reading anxiety (Saito, Garza, \& Horwitz, 1999) and foreign language anxiety (Horwitz, Horwitz, \& Cope, 1986). A review of the literature presented below emphasizes research on academically related student anxiety including student anxieties about foreign language, physics, and mathematics.

Horwitz, Horwitz, and Cope (1986) explored foreign language anxiety among students studying Spanish as a second language. Results indicated that the majority of the statements related to foreign language anxiety were supported by a third or more of the students surveyed. Students reported that they were afraid to speak in the foreign language, exemplified fear that they will not understand all foreign language and also feared being less competent than other students or being negatively evaluated by them. Khan, and Al-Mahrooqi (2015) found that students at the tertiary level were very anxious about speaking in classes due to a lack of exposure to English culture and that the level of anxiety resulting from fear of a teacher was higher than fear of peer evaluation. Afolayan, et al. (2013) reported that $50 \%$ of nursing students agreed that they perform better when they were not anxious than when they are anxious. Brantmeier (2005)'s study found that students at advanced level of language instruction reported being most anxious about speaking as opposed to writing, listening, and reading.

Previous research has indicated that there is general existence of a negative relationship between anxiety and achievement (MacIntyre, 1999). Other experts have noted that anxiety and nervousness, impair cognitive functioning, disrupt memory, and have other negative effects on students' learning (Eysenck, 1979; MacIntyre, \& Gardner, 1991). That's low levels of anxiety have been associated with increased achievement as opposed to higher levels of anxiety. MacIntyre (1999)'s synthesis of the literature on language anxiety indicates (among other findings) that language anxiety negatively correlates with second language achievement as well as self-perception and that anxious students spend more time studying. Also Saito, Garza, and Horwitz (1999) found that for students learning to read Japanese, French and Russian, the higher the self-reported level of foreign language reading anxiety, the lower the course grade, and vice versa. Czerniak and Chiarelott (1985) developed a science anxiety questionnaire and administered it to students of different grade levels. Among other findings the authors found that anxiety did not increase with grade level and that high level of science anxiety correlated with low science achievement scores. Spielberger (1980) found that individuals who had a higher levels of anxiety were less efficient in cognitive activities, such as school performance and learning. Anxious undergraduate students have been found to perform poorly on their writing tasks (Pajares, Britner, \& Valiante, 2000). Other researchers have reported that language anxiety negatively correlates with language course marks among first year credit courses in French-as-a-secondlanguage at a monolingual (English) Canadian university (MacIntyre \& Gardner, 1994). Sparks and Ganschow 
(2007) found that, amongst students who had studied three foreign languages: French, Spanish and German, the low anxious group scored significantly higher than the high anxious group on foreign language course grades. In an attempt to explain the reason why anxious students perform low on achievement tests, some researchers have argued that anxious individuals engage in task-irrelevant thoughts, which in turn consume some of their cognitive capacity (Eysenck, 1979). Sahin (2014) added that situations that create low levels of anxiety may sometimes enhance individual's achievement as opposed to those that create high degree of anxiety.

It might make sense to assume that anxiety levels are negatively correlated with course performance just as previous research has shown. Contrary to the later assumption, other researchers have found that higher levels of anxiety are associated with better course achievement (Khan, \& Al-Mahrooqi, 2015) and others have found no correlation at all (King, Heinrich, Stephenson, \& Spielberger, 1976). For example, Onwuegbuzie, Bailey, and Daley (1999) found that students with the highest levels of academic achievement also tend to have the highest level of foreign language anxiety. Likewise, Sahin (2014), found that students with high GPA had higher anxiety scores than students with medium GPA. Other researchers have found no correlations between anxiety and course achievement. For example, Khan and Al-Mahrooqi (2015) found that the level of anxiety was not related to the actual GFP level of the students. In a study by Diaz, et al. (2001), first year law students exemplified state anxiety which did not predict exam grades. Also Marcos-Llinás, and Juan-Garau (2009), found that students with high levels of anxiety did not actually exhibit lower course achievement in comparison to students with low levels of language anxiety. Alpert and Haber (1960) identified both positive and negative dimensions of anxiety among college freshmen; where the positive anxiety was described as "facilitating" and the negative anxiety was described as "debilitating". Several theories have been put forward to explain why high anxious students perform better, and the lack of correlation. For example, worry has the potential to increase motivation, and consequently performance (Eysenck, 1979). Onwuegbuzie, Bailey, and Daley (1999) argued that "facilitating" anxiety may also be a factor in explaining why anxious students perform better.

It also appears that it is hard for one to predict how anxiety may predict other variables based on their gender. In a study involving Turkish pre-service elementary teachers, it was found that there was no significant gender effect on science anxiety (Bursal, 2008). Similarly, Sağır (2012), found that there was no significant difference in anxiety between male and female primary school students. Yet other researchers (Chiarelott \& Czerniak, 1987; Czerniak, \& Chiarelott, 1985) found a gender difference in terms of anxiety (female students were more anxious than males). Alternatively, Sahin (2014) showed that there was no significant difference in physics anxiety between male and female students. However, when students were grouped into categories, it was shown that female students in physics education category obtained significantly higher physics anxiety scores. Mathew et al, (2013) found that there was no significant difference in the level of foreign language anxiety between males and females. In the field of nursing, Afolayan, et al. (2013), found that there was no statistical difference in terms of gender and academic performance of students, signifying that test anxiety equally affect both males and female.

\section{PROBLEM STATEMENT, RESEARCH QUESTIONS, AND HYPOTHESES}

According to the literature, there seems to be no clear results with respect to the role of anxiety in affecting student content performance. Most importantly there is no known research in the literature that has measured levels of student anxiety about physics vocabulary and its relationship with other variables such as students' course achievement and general classroom anxiety. Thus, this exploratory research developed a questionnaire to measure students' anxiety about physics vocabulary.

The researchers embarked into this project with some questions and associated hypotheses informed by related literature review and the researchers' own teaching experience. The first research question was; "what is the level and scope of anxiety that students have regarding intro level physics vocabulary?" Following previous related studies (e.g., Mallow, 1978; Suinn, \& Edwards, 1982), It was postulated that a higher percentage of introductory level physics students would report to be anxious about how physics is communicated.

The second research question inquired whether or not there is a relationship between; (i) anxiety about physics vocabulary and student achievement, and (ii) general classroom anxiety and physics vocabulary anxiety. Despite the inconclusiveness of the findings in the literature about the role of anxiety on student performance, following Czerniak and Chiarelott (1985)'s results, the researchers made an assumption that high anxiety about the physics vocabulary (as measured by the Physics Vocabulary Classroom Anxiety Scale (PVCAS)) should negatively correlate with student grades (as measured by the Force Concept Inventory (FCI)). Consequently, the researchers anticipated that students who are very anxious would likely get lower grades on the FCI. Moreover, the researchers also assumed that a student who is anxious about physics vocabulary is likely to be anxious in general. Here they assumed a positive correlation between physics vocabulary and general classroom anxiety (which was measured using the Classroom Test of Anxiety (CAT)). 
Table 1. Transformation of FLCAS Items to PVCAS Items

\begin{tabular}{ll}
\hline The FLCAS Item & The PVCAS item \\
\hline $\begin{array}{ll}\text { "It frightens me when I don't understand what the } \\
\text { teacher is saying in the non-native language." }\end{array}$ & $\begin{array}{l}\text { "It frightens me when I don't understand what the teacher is saying in } \\
\text { the language of physics." }\end{array}$ \\
\hline $\begin{array}{l}\text { "I am afraid that my language teacher is ready to } \\
\text { correct every mistake I make." }\end{array}$ & "I am afraid that my physics teacher is ready to correct every physics \\
language mistake I make."
\end{tabular}

\section{METHOD}

This section presents how the above research questions were answered. A description of research participants is provided followed by research instruments then procedure.

\section{Participants}

Twenty-one undergraduate college students enrolled in an introductory physics course took part in the research. Students' age ranged from 18 to 24, fourteen females and seven males. Eight students spoke English as their first language while thirteen students as their second language. Students' majors included education, liberal arts, visual arts, science, and business. The student population is among one of the most diverse population in the country. According to the school 2017-2018 Fact Books, there were 15, 400 students enrolled coming from a total of 127 countries with $34 \%$ of the students reporting speaking a language other than English at home. In fall 2017 Spanish, Chinese, Begali, Urdu, and Creole were the most prevalent languages spoken at home. Due to the diverse linguistic background of the student population, many of the freshmen students attend remedial writing (21\%) and remedial reading $(11 \%)$ courses to improve their skills in academic English. This project was approved by the Institution Review Board (IRB) and that the necessary ethical procedures (e.g., consent administration and voluntary participation) were followed.

\section{Research Instruments}

Several research instruments (presented below) were used to answer the research questions.

Physics Vocabulary Classroom Anxiety Scale (PVCAS). The PVCAS was created to assess whether students display anxiety about the physics vocabulary and consequently perform the necessary correlations. The design of the PVCAS was modelled from the Foreign Language Classroom Anxiety Scale (FLCAS) by Horwitz, Horwitz, and Cope (1986). Note that the FLCAS was initially created to examine the scope and severity of foreign language anxiety. The FLCAS is a 33-question self-report questionnaire that uses a Likert scale to assess issues related to communication apprehension, test anxiety, and fear of negative evaluation. Each item on the questionnaire requires a student to circle one of the following options: Strongly Disagree (SD), Disagree (D), Neither Agree Nor Disagree (NAD) or Strongly Agree (SA). Since the scale was initially designed to assess language anxiety for students taking a foreign language, the scale was modified to assess physics language/vocabulary anxiety for students studying introductory physics. The FLCAS items were modified to better answer the research questions for the project under consideration. Table 1 shows exemplar FLCAS items and how they were modified for our purposes.

The original version of the Physics Vocabulary Anxiety Scale (PVCAS) consisted of 31 questions (See the Appendix A). A Principle Component Analysis (PCA) with a promax oblique rotation was performed on this initial version to establish how questions were grouped together statistically in possible components. Following Tabachnick and Fidel (2001), the majority of correlations between the different questions were above .3 indicating the relevance of the application of the PCA to the questionnaire. The number of PCA components was limited to two and all the questions with a factor loading above .3 were retained The PCA results showed that all questions in the first component were related to the construct of anxiety whereas the questions in the second component were a mixture of confidence about physics terminology and physics course. However, because the interest was only on the anxiety construct, all the items (that were not directly related to the construct of anxiety or that were poorly worded which could possibly lead to ambiguous interpretations by students) were eliminated from the original questionnaire. The original questionnaire was then reduced to 16 questions (see Appendix B). The PCA on the 16 questions showed that total variance for the 16 questions was $62.41 \%\left(51.79 \%\right.$ for $1^{\text {st }}$ component and $10.62 \%$ for second one) with the correlation between the two components being high $r=.6$. Also the Kaiser-Meyer-Olkin $(\mathrm{KMO})$ measuring sample adequacy turned out to be moderately adequate (.6) and the Bartlett's Test of Sphericity $\left(\chi^{2}(325.4)=171, p<.000\right)$ significant, showing that there was a good relation between the analyzed variables. Given the positive values for KMO and Bartlett's Test, the data show a good suitability for the structure detection analysis (PCA). Finally, the Cronbach's alpha was measured for these 16 questions; the value was very high $(\alpha=.9)$ showing, that the PVCAS has excellent reliability. 
As for scoring the PVCAS, numbers were assigned to each option: $\mathrm{SA}=5, \mathrm{~A}=4, \mathrm{NAD}=3, \mathrm{D}=2$, and $\mathrm{SD}=1$. The PVCAS score for each student was found by adding up all the numbers for all the 16 items. Thus, the larger the PVCAS score roughly corresponds to the larger anxiety in physics vocabulary. In order to measure whether the anxiety towards the physics vocabulary correlates with student performance the PVCAS scores were correlated with the scores on the Force Concept Inventory (FCI) by (Hake, 1998). Finally, the research also focused on assessing whether there is a relationship between general classroom anxiety and physics vocabulary anxiety. For this, the Classroom Anxiety Test (CAT) scores were used.

\section{Force Concept Inventory (FCI)}

Student learning achievements were obtained using the FCI (Hake, 1998); a well-known and widely used tool in physics education, consisting of 30 multiple choice questions intended to assess students' conceptual understanding of force and motion (mechanics).

\section{Classroom Test of Anxiety (CAT)}

The CAT was created by Richmond et al. (2001) to measure student's anxiety in a classroom. It is based on Richmond's Situational Communication Apprehension Measure (RSCAM). The expected alpha reliability on this measure is about .90. The scoring for the CAT was done following instructions provided by the authors (total score $=100$; the larger the score the higher the classroom anxiety).

\section{Procedure}

During the course of the semester students were asked to fill out various questionnaires and a mechanics inventory. Students filled out the Classroom Anxiety Test (CAT) during the first week of the semester (Pre CAT) and then again the last week of the semester (Post CAT) to measure their level of classroom anxiety. Similarly, students took the Force Concept Inventory (FCI) at the beginning of the class (pretest) and at the end of the class (posttest). Students took the Physics Vocabulary Classroom Anxiety Scale (Pre PVCAS) after going through most of the mechanics topics and they retook the test the last week of class (Post PVCAS). Additional mechanics topics were taught between the pre PVCAS and the Post PVCAS. Note that the CAT and the PVCAS were administered pre and post to gauge their reliability; no aspect of "intervention" is implied.

\section{RESULTS}

To answer the research questions, basic descriptive statistics coupled with relevant correlations (correlational research) were employed. Pretest scores were correlated with posttest scores and scores for a one questionnaire/group of students were correlated with scores from another questionnaire/group of students.

The first task of this research was to gauge the level and scope of physics vocabulary anxiety that students have. Results are presented using the post PVCAS survey that students completed after covering several mechanics topics. It should be mentioned that there was a positive correlation between the pre PVCAS and the post PVCAS $(r$ $=.5$ ) indicating the applicability of the instrument in measuring anxiety in physics vocabulary. Table 2 presents the mean standard deviation and median of 16 questions.

Table 2 shows that on average students neither agree nor disagree with the 16 statements. The overall mean and $S D$ were $M=2.9(1.07)$. The $S D$ suggests that there is a variation among students with regards to the level of anxiety towards the language of physics. 
Taibu \& Ferrari-Bridgers / Anxiety About the Jargon of Physics

Table 2. Item-statistics: Mean, Standard Deviation, and Median

\begin{tabular}{ccc}
\hline & $\boldsymbol{M}(\boldsymbol{S D})$ & Median \\
\hline Q1 & $3.19(1.12)$ & 3 \\
\hline Q2 & $3(.89)$ & 3 \\
\hline Q3 & $3.19(.98)$ & 3 \\
\hline Q4 & $2.8(.87)$ & 3 \\
\hline Q5 & $3.28(1)$ & 3 \\
\hline Q6 & $3.00(.94)$ & 2 \\
\hline Q8 & $2.47(.98)$ & 2 \\
\hline Q9 & $2.76(.94)$ & 2 \\
\hline Q10 & $3.00(1.14)$ & 3 \\
\hline Q11 & $2.80(.98)$ & 3 \\
\hline Q12 & $3.04(1.11)$ & 3 \\
\hline Q13 & $3.19(1.20)$ & 3 \\
\hline Q15 & $2.76(.94)$ & 2 \\
\hline Q16 & $2.80(1.12)$ & 4 \\
\hline Total & $3.38(1.07)$ & 2 \\
\hline & $2.38(1.00)$ & 2.75 \\
\hline
\end{tabular}

Table 3. Scoring of the Physics Vocabulary Classroom Anxiety (PVCAS)

$$
\text { SD } D \text { N } A \text { SA }
$$

1. It frightens me when I don't understand the physics terms.

$$
14 \% \quad 38 \% \quad 24 \% \quad 24 \% \quad 0 \%
$$

2. I start to panic when I have to define terms without preparation in physics class.

$$
0 \% \quad 48 \% \quad 33 \% \quad 19 \% \quad 0 \%
$$

3. In physics class, I can get so nervous if I forget the technical terms I know.

$$
5 \% \quad 57 \% \quad 10 \% \quad 24 \% \quad 5 \%
$$

4. It embarrasses me to volunteer answers in my physics class.

$$
0 \% \quad 14 \% \quad 29 \% \quad 52 \% \quad 5 \%
$$

5. I get upset when I don't understand what the teacher is correcting.

$$
14 \% \quad 48 \% \quad 14 \% \quad 24 \% \quad 0 \%
$$

6. Even if I am well prepared for physics class, I feel anxious about the physics terminology

$$
5 \% \quad 57 \% \quad 14 \% \quad 19 \% \quad 5 \%
$$

7. I am afraid that my physics instructor is ready to correct every physics vocabulary mistake I make.

$$
0 \% \quad 14 \% \quad 33 \% \quad 48 \% \quad 5 \%
$$

8. I can feel my heart pounding when the instructor is going to call me to answer a question in the physics class. $5 \% \quad 24 \% \quad 38 \% \quad 24 \% \quad 10 \%$

9. The more I study for a physics test, the more confused I get. $5 \% \quad 29 \% \quad 29 \% \quad 38 \% \quad 0 \%$

10. I always feel that the other students speak the technical language of physics better than I do.

$$
0 \% \quad 38 \% \quad 48 \% \quad 14 \% \quad 0 \%
$$

11. I feel very self-conscious about speaking the technical language of physics in front of other students.

$$
0 \% \quad 24 \% \quad 38 \% \quad 38 \% \quad 0 \%
$$

12. I feel more tense and nervous in my physics class than in my other classes due to the vocabulary of physics.

$19 \% \quad 38 \% \quad 19 \% \quad 19 \% \quad 5 \%$

13. I get nervous and confused when I am speaking the technical language of physics in class.

$0 \% \quad 38 \% \quad 33 \% \quad 24 \% \quad 5 \%$

14. I get nervous when I don't understand every physics term the physics instructor says.

$14 \% \quad 48 \% \quad 14 \% \quad 24 \% \quad 0 \%$

15. I feel overwhelmed by the number of definitions/terminology you have to learn to understand physics $19 \% \quad 48 \% \quad 14 \% \quad 19 \% \quad 0 \%$

16. I am afraid that the other students will laugh at me when I speak the technical language of physics.

$\begin{array}{lllll}0 \% & 0 \% & 43 \% & 57 \% & 0 \%\end{array}$

Such a variation is captured in Table 3, which provides the percentage of students choosing the various options (levels of agreement or disagreement).

As the results showed, a larger percentage of students reported to be anxious about physics terminology. For the entire survey, $41 \%$ of students agree or strongly agree vs. $31 \%$ of students who disagreed or strongly disagreed 
Table 4. Correlations among Post PVCAS, CAT and FCl

\begin{tabular}{cccc}
\hline & $\boldsymbol{F C l}$ & CAT & PVCAS \\
\hline FCl & 1 & -.191 & -.175 \\
\hline CAT & & 1 & .395 \\
\hline $\mathrm{P}<.05$ & & & 1 \\
\hline & & &
\end{tabular}

Table 5. Non-Native and Native Students Mean and Standard Deviation on PVCAS, CAT and FC

\begin{tabular}{ccc} 
& Non Native Speakers $(\mathbf{N}=\mathbf{1 3})$ & Native Speakers $(\mathbf{N}=\mathbf{8})$ \\
\hline & Pre Post Mean $(S D)$ & Pre Post Mean $(S D)$ \\
\hline PVCAS & $48.3(8.6) 45(9.6)$ & $53.1(5.6) 48.1(14.3)$ \\
\hline CAT & $46.2(8.1) 46.7(10.2)$ & $48.8(16) 54(9.8)$ \\
\hline FCI & $5.3(4.5) 14.6(6.5)$ & $7.7(4.7) 14.8(5.4)$ \\
\hline
\end{tabular}

that they are anxious about how physics is communicated. The rest are neutral on this matter. A thorough discussion regarding this is provided in the discussion section of the paper.

Correlations between the PVCAS scores and other variables (CAT and FCI) were computed as a series of bivariate correlation and a regression analysis. Table 4 presents the resulting correlations.

Before this research, it was hypothesized that students with high anxiety levels about physics vocabulary should obtain lower scores on the FCI. The results indicated the presence of a small and negative correlation $(r=-.2)$ which was not statistically significant. This implies that the level of anxiety about physics vocabulary does not correlate with student achievement for the student population. Interestingly, the same conclusions can be obtained for the correlation between the CAT and the students' grades $(r=-.2)$ confirming that classroom anxiety also did not correlate with student performance. As far as the relation between the CAT and the PVCAS, there was a moderate correlation between the CAT and the PVCAS $(r=.4)$ suggesting that the two types of anxieties are both present among the student population, despite their lack of significance on the student performance.

A regression analysis was performed to assess how much of the student performance was affected by both types of anxieties. The two anticipated predictors for grade, CAT and PVCAS, explained only $5 \%$ of the variance $\left(R^{2}=\right.$ $.048, F(2.18)=, p<\mathrm{np}$ ) further confirming the lack of influence of anxiety on the student population.

The last research question explored whether the level of physics vocabulary anxiety depends on students being native or non-native English speakers. Table 5 indicates that the mean difference in PVCAS, CAT and FCI average scores between the two groups (native and non-native students).

According to the data, the mean score difference between both groups in the pre and posttests is quite small, with non-native students scoring lower than natives. However given that both PVCAS and CAT answers are based on a Likert scale, to test the significance of such a quite small difference, a Wilcoxon signed Ranks Test was performed on the post PVCAS and the post CAT results between Native and Non Native English speakers. The Wilcoxon test for both variables indicated that there was no significant difference in level of anxiety about the physics vocabulary between the Native Post PVCAS and Post CAT ranks and the Non Native English Speakers' Post PVCAS ranks, $\left(Z_{P V C A S}=0, p<n p ; Z_{C A T}=-1.3, p<n p\right)$.

The lack of significant difference between the two groups for both variables also explains why Native and Non Native English speaking Students scored almost identically on the FCI.

\section{DISCUSSION}

Students' responses to the physics vocabulary anxiety survey clearly demonstrates that they are generally anxious about physics vocabulary just as they are anxious about different academic issues. Of course student responses varied across different items of the survey indicating that students not only agreed but also disagreed on some assertions of the items (Table 2). For example, for item 1, results indicate that a large percentage of students are frightened about not understanding the physics terms (52\% agree or strongly agree vs $24 \%$ disagree or strongly disagree). For item 2, a large percentage of students think they start to panic when they try to define physics terms $(48 \%$ A or SA vs. $19 \%$ D). Item 3 results show that a larger percentage of students get so nervous if they forget the technical terms of physics (62\% A or SA vs. $29 \%$ D or SD). Similar items follow the same pattern; having a larger percentage of students nodding to the fact that the vocabulary of physics makes them anxious. A closer look at most of these items indicates that they are directly related to students' fear of not understanding the terminology. This is similar to the idea of fear of "communication apprehension" coined by Horwitz et al. (1986). Few items on the survey indicate the opposite student distribution with most students disagreeing to the item. For example; item 4 analysis ("It embarrasses me to volunteer answers in my physics class."), indicates that no student agreed to this while $57 \%$ disagreed. Likewise, no student agreed that they are afraid that the other students will laugh at them 
when they speak the technical language of physics (Item 16). This indicates that it's not just a "mere anxiety" that is important but the "source of anxiety" matters. Contrary to previous related findings (Al-Saraj, 2014) few of the students reported uneasiness due to teacher or peer evaluation, instead most were anxious about the physics terminology itself (see Table 2).

Item 14 clearly indicates that students are not only anxious about the terminology but also the amount of terminology. Thus, it is observed that a huge percentage of students (67\%) agree or strongly agree that they feel overwhelmed by the number of definitions/terminology they have to learn to understand physics. The anxiety distribution is similar to previous related studies on foreign language anxiety (Horwitz, Horwitz, \& Cope, 1986). The items in the PVCAS were reflective of communication apprehension, test-anxiety, and fear of negative evaluation in physics vocabulary.

Regarding correlations between the PVCAS and student achievement, results are somehow at odds with suggested hypotheses. There was a negative but small correlation between physics vocabulary anxiety and physics performance $(r=-2)$. Previous studies have reported a complex and/or no relationship between task performance anxiety (Diaz, Glass, Arnkoff, \& Tanofsky-Kraff, 2001; Khan, \& Al-Mahrooqi, 2015; King, Heinrich, Stephenson, \& Spielberger, 1976; Sahin, 2014) while others have reported a negative relation (MacIntyre, 1999) and yet other a positive correlation (Onwuegbuzie, Bailey, \& Daley, 1999). This research adds more to the nonlinear nature of academic anxiety and course performance and partly to the negative correlation between anxiety and achievement.

It was interesting to see that the anxiety about physics vocabulary, moderately correlated with the general classroom anxiety test (as measured by the CAT). Although there was an anticipation for a larger correlation, a case can be made regarding how physics is communicated and its potential effects on students' affective domain including general classroom mood. A student who is bombarded with the technical language throughout the learning process is likely to feel uneasiness in such a classroom.

One may easily assume that non-native English speaking students would be more anxious about how physics is traditionally communicated than native English speaking students. Even the researcher's own experience interacting with these students for so long point to the fact that nonnative English speaking students are more likely to be anxious in an introductory physics class. The current research departs from the later assumptions, probably because these students are already comfortable with both languages (native and nonnative) or that they felt ashamed to truthfully report their anxiety levels.

\section{RESEARCH IMPLICATIONS}

One may wonder why studying anxiety (which is related to affective domain) is important when its relationship with cognitive domain is unclear. Previous researchers (e.g., Eysenck, 1979; Phillips, 1992) have asserted that ignoring anxiety issues is dangerous regardless of its vagueness in terms of how it relates to course achievement. Phillips (1992) reminds educators not to be too much concerned only with course achievement but also students' affective reactions, which affect their attitudes towards a given subject. Eysenck (1979) worried that most anxiety research is focused exclusively on its relationship with task performance and may consequently overlook effects in other areas. Consequently, the introductory level students exemplified anxiety which needs to be dealt with so as to set a good attitude towards physics.

The finding that students were more anxious about the physics terminology than peer or teacher evaluation implies that educators should prioritize inculcation of physics terminology by encouraging peer instruction or by engaging students in classroom discussions. Student anxiety in this research moderately correlated with general classroom anxiety indicating that student anxiety is something worthy studying in education besides the cognitive domain. The vocabulary of physics is generally troublesome among educators as well as students; it may hinder or facilitate understanding at the same time it makes students anxious. Whether this anxiety is "debilitating" or "facilitating", educators ought to craft introductory level physics classes to make learning enjoyable for students.

\section{CONCLUSION}

According to this exploratory research, a relatively larger percentage of students were anxious about the way physics is communicated leading to comprehension difficulties. Specifically, some students reported to be anxious about not understanding the physics terms, others reported that they start to panic when they try to define physics terms and yet others reported that they get so nervous if they forget the technical terms of physics. On the contrary, most students did not report to feel embarrassed or nervous to volunteer answers in a physics class despite facing difficulties with the technical language. Thus, most students did not report uneasiness due to teacher or peer evaluation, but were anxious about the physics terminology itself. Results of the research also indicated that there was a negative but small correlation between anxiety about physics jargon and student performance on a conceptual mechanics test (student achievement) while the correlation between anxiety about physics jargon and 
general classroom anxiety was moderate. Finally, there was no significant difference in levels of anxiety about the physics vocabulary between native and nonnative English-speaking students.

\section{LIMITATIONS}

It should be noted that there are limitations to this research. The first limitation relates to the sample size used for this research. Therefore, more data needs to be collected to confirm the initial findings. The second limitation of this research relates to the fact that students self-reported their feelings. This might have made them feel embarrassed as they responded to items which are physiological/behavioral in nature. Some students may have tried to save face and consequently underrated their anxiety levels. Future studies on this subject will therefore collect more and additional data (e.g., group discussions, interviews, and observations) to increase the sample size and to employ mixed research methods. The suggested approach could provide more insight into students' perceptions on how physics is communicated.

\section{ACKNOWLEDGEMENT}

Support for this project was provided by a PSC-CUNY Award, jointly funded by The Professional Staff Congress and The City University of New York.

\section{REFERENCES}

Afolayan, J. A., Donald, B., Onasoga, O., Babafemi, A., \& Agama Juan, A. (2013). Relationship between anxiety and academic performance of nursing students. Advances in Applied Science Research, 4(4), 25-33.

Al-Saraj, T. M. (2014). Revisiting the foreign language classroom anxiety scale (FLCAS): The anxiety of female English language learners in Saudi Arabia. L2 Journal, 6(1), 50-76. https:/ / doi.org/10.5070/L26121650

Brantmeier, C. (2005). Anxiety about L2 reading or L2 reading tasks? A study with advanced language learners. Reading, 5(2), 67-85.

Bursal, M. (2008). Changes in Turkish pre-service elementary teachers' personal teaching efficacy beliefs and science anxieties during a science method course. Journal of Turkish Science Education, 5(1), 99-112.

Cebreros, A. M. O. (2003). Measuring language anxiety perceived by Spanish university students of English. Bells: Barcelona English Language and Literature Studies. Retrieved from http:/ / www.publicacions.ub.edu/revistes/bells12/pdf/art11.pdf

Chiarelott, L., \& Czerniak, C. (1987). Science anxiety: Implications for science curriculum and teaching. The Clearing House, 60(5), 202-205. https:/ / doi.org/10.1080/00098655.1987.9959323

Czerniak, C., \& Chiarelott, L. (1985). Science anxiety among elementary school students: Equity issues. Journal of Educational Equity and Leadership, 5(4), 291-308.

Diaz, R. J., Glass, C. R., Arnkoff, D. B., \& Tanofsky-Kraff, M. (2001). Cognition, anxiety, and prediction of performance in 1st year law. Journal of Educational Psychology, 93(2), 420-429. https:/ / doi.org/10.1037/00220663.93.2.420

Ellis, R. (2008). The study of second language acquisition (2nd ed.). Oxford: OUP.

Eysenck, M. W. (1979). Anxiety, learning and memory: A reconceptualization. Journal of Research in Personality, 13(4), 363-385. https:/ / doi.org/10.1016/0092-6566(79)90001-1

Gardner, R. C. (1985). Social psychology and second language learning: The role of attitudes and motivation. Arnold. Baltimore, USA.

Hake, R. R. (1998). Interactive-engagement versus traditional methods: A six-thousand-student survey of mechanics test data for introductory physics courses. American Journal of Physics, 66(64), 64-74. https://doi.org/10.1119/1.18809

Horikawa, M., \& Yagi, A. (2012). The relationships among trait anxiety, state anxiety and the goal performance of penalty shoot-out by university soccer players. PloS One, 7(4), e35727. https:// doi.org/10.1371/journal.pone.0035727

Horwitz, E. K., Horwitz, M. B., \& Cope, J. (1986). Foreign language classroom anxiety. The Modern Language Journal, 70(2), 125-132. https:// doi.org/10.1111/j.1540-4781.1986.tb05256.x

Khan, A., \& Al-Mahrooqi, R. (2015). Foreign language communication anxiety (FLCA) among tertiary level Omani EFL learners. The Asian EFL Journal Quarterly March 2015, 17(57). 
King, F. G., Heinrich, D. L., Stephenson, R. S., \& Spielberger, C. D. (1976). An investigation of the causal influence of trait and state anxiety on academic achievement. Journal of Educational Psychology, 68(3), 330-334. https:/ / doi.org/10.1037/0022-0663.68.3.330

MacIntyre, P. D. (1999). Language anxiety: A review of the research for language teachers. In Young, D. J. (Ed.), Affect in foreign language and second language learning: a practical guide to creating a low-anxiety classroom atmosphere (pp. 24-45). New York: McGraw Hill.

MacIntyre, P. D., \& Gardner, R. C. (1991). Methods and results in the study of anxiety and language learning: A review of the literature Language Learning, 41(1), 85-117. https://doi.org/10.1111/j.14671770.1991.tb00677.x

MacIntyre, P. D., \& Gardner, R. C. (1994). The subtle effects of language anxiety on cognitive processing in the second language. Language Learning, 44(2), 283-305. https:/ / doi.org/10.1111/j.1467-1770.1994.tb01103.x

Mallow, J. V. 1978. (1978). A science anxiety program. American Journal of Physics, 46, 862. https://doi.org/10.1119/1.11409

Marcos-Llinás, M., \& Juan-Garau, M. (2009). Effects of language anxiety on three proficiency-level courses of Spanish as a Foreign Language. Foreign Language Annals, 42(1), 94-111. https://doi.org/10.1111/j.19449720.2009.01010.x

Onwuegbuzie, A. J., Bailey, P., \& Daley, C. E. (1999). Factors associated with foreign language anxiety. Applied Psycholinguistics, 20(2), 217-239. https:// doi.org/10.1017/S0142716499002039

Pajares, F., Britner, S. L., \& Valiante, G. (2000). Relation between achievement goals and self-beliefs of middle school students in writing and science. Contemporary Educational Psychology, 25(4), 406-422. https:/ / doi.org/10.1006/ceps.1999.1027

Phillips, E. M. (1992). The effects of language anxiety on students' oral test performance and attitudes. The Modern Language Journal, 76(1), 14-26. https:/ / doi.org/10.1111/j.1540-4781.1992.tb02573.x

Randler, C. (2009). Association between emotional variables and school achievement. International Journal of Instruction, 2(2), 3-10.

Richmond, V. P., Wrench, J. S., \& Gorham, J. (2001). Communication, affect, and learning in the classroom. Acton, MA: Tapestry Press.

Rosenthal, J. W. (1996). Teaching science to language minority students: Theory and practice (Vol. 3). Bristol, PA: Multilingual matters Ltd.

Sağır, Ş. U. (2012). The primary school students' attitude and anxiety towards science. Journal of Baltic Science Education, 11(2), 127-140.

Sahin, M. (2014). The relationship between pre-service teachers' physics anxiety and demographic variables. Journal of Baltic Science Education, 13(2), 201-215.

Saito, Y., Garza, T. J., \& Horwitz, E. K. (1999). Foreign language reading anxiety. The Modern Language Journal, 83(2), 202-218. https:/ / doi.org/10.1111/0026-7902.00016

Sparks, R., \& Ganschow, L. (2007). Is the Foreign Language Classroom Anxiety Scale (FLCAS) measuring anxiety or language skills? Foreign Language Annals, 40, 260-287. https:/ / doi.org/10.1111/j.1944-9720.2007.tb03201.x

Spielberger, C. (1980). Preliminary professional manual for test anxiety inventory. Palo Alto, CA: Consulting Psychologist Press.

Spielberger, C. D. (1983). Manual or the State-Trait Anxiety Inventory. Palo Alto, CA: Consulting Psychologists Press. https:/ / doi.org/10.1037/t06496-000

Spielberger, C. D. (1996). Anxiety and behavior. New York: Academic Press.

Suinn, R. M., \& Edwards, R. (1982). The measurement of mathematics anxiety: The mathematics anxiety rating scale for adolescents-MARS-A. Journal of Clinical Psychology, 38(3), 576-580. https://doi.org/10.1002/10974679(198207)38:3<576::AID-JCLP2270380317>3.0.CO;2-V

Tabachnick, B. G., \& Fidel, L. S. (2001). Using multivarite statistics. Needham Heights, MA: Allyn 8.

Taibu, R. (2015). A Study of Conceptual and Language Issues Surrounding Weight, Weightlessness, and Free Fall: Textbook Analysis, Instructional Design, and Assessment.

Taibu, R., Schuster, D., \& Rudge, D. (2017). Teaching weight to explicitly address language ambiguities and conceptual difficulties. Physical Review Physics Education Research, 13(1), 010130. https:/ / doi.org/10.1103/PhysRevPhysEducRes.13.010130

Williams, H. T. (1999). Semantics in teaching introductory physics. American Journal of Physics, 67(8), 670-680. https://doi.org/10.1119/1.19351 
Wolman, B. B. (1973). Dictionary of behavioral science. New York: (Van Nostrand Reinhold Company.

Yaman, H. (2010). Writing anxiety of Turkish students: scale development and the working procedures in terms of various variables. International Online Journal of Educational Sciences, 2(1), 267-289.

\section{APPENDIX A}

The Original PVCAS Questionnaire (See Table 3 for the final version of the questionnaire)

1. I never feel quite sure of myself using physics terms in classroom communication.

2. I don't worry about making physics vocabulary mistakes in class.

3. I tremble when I know that the instructor is going to ask me a question in physics class.

4. It frightens me when I don't understand the physics terms.

5. During physics class, I find myself thinking about things that have nothing to do with the course.

6. I keep thinking that the other students are better at the physics terms than I am.

7. I am usually at ease during tests in my physics class.

8. I start to panic when I have to define terms without preparation in physics class.

9. I worry about the consequences of failing to define physics terms.

10. I don't understand why some people get so upset over the technical terms of physics.

11. In physics class, I can get so nervous if I forget the technical terms I know.

12. It embarrasses me to volunteer answers in my physics class.

13. I would not be nervous speaking the technical language of physics with physics experts.

14. I get upset when I don't understand what the teacher is correcting.

15. Even if I am well prepared for physics class, I feel anxious about the physics terminology.

16. I often feel like not going to my physics class.

17. I feel confident when I speak the technical language of physics in class.

18. I am afraid that my physics instructor is ready to correct every physics vocabulary mistake I make.

19. I can feel my heart pounding when the instructor is going to call me to answer a question in the physics class.

20. The more I study for a physics test, the more confused I get.

21. I don't feel pressure to prepare very well for physics class.

22. I always feel that the other students speak the technical language of physics better than I do.

23. I feel very self-conscious about speaking the technical language of physics in front of other students.

24. Physics class moves so quickly I worry about getting left behind.

25. I feel more tense and nervous in my physics class than in my other classes.

26. I get nervous and confused when I am speaking the technical language of physics in class.

27. When I'm on my way to physics class, I feel very sure and relaxed.

28. I get nervous when I don't understand every physics term the physics instructor says.

29. I feel overwhelmed by the number of definitions/terminology you have to learn to understand physics.

30. I am afraid that the other students will laugh at me when I speak the technical language of physics.

31. I would probably feel comfortable around those who are good at the physics vocabulary. 


\section{APPENDIX B}

\section{The PVCAS Questionnaire}

17. It frightens me when I don't understand the physics terms.

18. I start to panic when I have to define terms without preparation in physics class.

19. In physics class, I can get so nervous if I forget the technical terms I know.

20. It embarrasses me to volunteer answers in my physics class.

21. I get upset when I don't understand what the teacher is correcting.

22. Even if I am well prepared for physics class, I feel anxious about the physics terminology.

23. I am afraid that my physics instructor is ready to correct every physics vocabulary mistake I make.

24. I can feel my heart pounding when the instructor is going to call me to answer a question in the physics class.

25. The more I study for a physics test, the more confused I get.

26. I always feel that the other students speak the technical language of physics better than I do.

27. I feel very self-conscious about speaking the technical language of physics in front of other students.

28. I feel more tense and nervous in my physics class than in my other classes due to the vocabulary of physics.

29. I get nervous and confused when I am speaking the technical language of physics in class.

30. I get nervous when I don't understand every physics term the physics instructor says.

31. I feel overwhelmed by the number of definitions/terminology you have to learn to understand physics

32. I am afraid that the other students will laugh at me when I speak the technical language of physics.

\section{http://www.ejmste.com}

